\title{
Adsorption of Tartrazine on Medical Activated Charcoal Tablets under Controlled Conditions
}

\author{
Mohammed A Kassem ${ }^{1,2 *}$ and Gamal O El-Sayed ${ }^{1}$ \\ ${ }^{1}$ Departmentof Chemistry, Faculty of Science, Benha University, Benha, Egypt \\ ${ }^{2}$ Departmentof Chemistry, Faculty of Applied Sciences, Umm Al-Qura University, Makkah, Saudi Arabia
}

\begin{abstract}
Two types of commercial medical tablets of activated charcoal formulations (AC1 and AC2) were used as adsorbents for tartrazine. The adsorption studies were performed at controlled conditions of $\mathrm{pH}$, and temperature (gastrointestinal-like conditions). It was found that $\mathrm{pH}$ plays a major role in the adsorption process. At $\mathrm{pH} 1.5$ and $37^{\circ} \mathrm{C}$ the effect of different parameters affecting dye removal (salinity, adsorbent dose, initial dye concentration and stirring rate) were examined. The effects of some dietary additives like mono- and disaccharides, artificial sweeteners and glycine on the adsorption efficiency were assayed. The maximum adsorption of tartrazine on activated carbon tablets was observed at highly acidic media. The removal efficiency appears to decrease with increasing temperature and salinity indicating an exothermic process. Equilibrium adsorption isotherms for the removal of tartrazine from aqueous solution using activated charcoal tablets have been investigated. Langmuir and Freundlich's models were applied to the data related to adsorption isotherms. According to Langmuir's model data, the observed maximum adsorption capacities $\left(q_{\mathrm{m}}\right)$ were 272.85 and $456.83 \mathrm{mgg}^{-1}$ at $37^{\circ} \mathrm{C}$ for AC1 and AC2, respectively. Medical activated charcoal tablets appear as a very prospective adsorbent for the removal of tartrazine from aqueous solution.
\end{abstract}

Keywords: Medical formulations; Activated charcoal; Tartrazine; Adsorption; Isotherm

\section{Introduction}

Tartrazine, (E102 or FD\&C Yellow 5) is one of the most commonly used food additives. It is found in the following food stuffs: soft drinks, instant puddings, flavored chips, custard powder, soups, sauces, ice cream, candy, chewing gum, jam, jelly, marmalade, mustard, yogurt and many other convenience foods. Other non-nutritional products like vitamins, antacids, medicinal capsules also can contain tartrazine. For the humans, tartrazine is considered a highly toxic material and can act as catalyst in hyperactivity [1] and other behavioral problems [2]. It may also cause asthma, eczema, thyroid cancer and lupus [3,4]. Tartrazine appears to cause the most allergic reactions of all the azo dyes. Other harmful reactions can include migraine, blurred vision and itching [5-7]. Tartrazine sensitivity is mainly manifested by urticaria. It possesses high water solubility, which maximizes its harmful effects. The adsorption of tartrazine has been studied by several adsorbents like hen feathers [8], bottom ash and de-oiled soya [9], polystyrene anion exchange resins [10], multi walled carbon nanotubes [11] and activated carbon [12].

The most common industrial adsorbent is activated carbon. It is the oldest adsorbent known and is usually prepared from using one of the two basic activation methods; physical and chemical [13]. Adsorption on activated charcoal (AC) is widely employed for removal of colors and organic pollutants due to its extended surface area, microporus structure, high adsorption capacity and high degree of surface reactivity $[14,15]$.

Activated charcoal, due to its strong adsorption properties can be effective in binding with some harmful substances in the stomach and intestine. In case of poisoning, activated charcoal can absorb or hold the toxin to its surface, and prevent its absorption in the digestive tract. It can be also used for the treatment of drug overdose as well. However, the activated charcoal that is used in the case of poisoning usually comes in powder form or just suspended in a liquid. Charcoal tablets are also used for digestive ailments, especially for indigestion, diarrhea and flatulence. Activated charcoal can absorb excess gas in the stomach and intestine and thereby, alleviate bloating, flatulence and heartburn. Activated charcoal can interact with certain medications or affect their absorption in the intestinal tract. Therefore, it is better not to take medications one or two hours before and after taking activated charcoal tablets $[16,17]$.

The present study aimed to examine the ability of oral medical formulations of activated charcoal to remove toxic tartrazine food coloring dye by adsorption under stomach-like conditions. The study has been carried out under different variables, as $\mathrm{pH}$, temperature, adsorbent dose and dye concentration. The effect of salinity and some additives usually present in stomach as mono- and disaccharides, saccharine and aspartame, and some surfactants were examined at strong acidic solutions at $37^{\circ} \mathrm{C}$.

\section{Experimental}

\section{Reagents and solutions}

Medical carbon tablets: Eucarbon ${ }^{\circ} \mathrm{AC1}$ ) and Neo Carbotrina (AC2) were obtained from SEDICO Pharmaceutical Company (6 October City, Egypt) and The Arab Drug Company ADCO (El Amiriya, Egypt), respectively. Five tablets of each formulation of the compositions shown in Table 1 , were crushed and homogenized to a uniform size $(\leq 0.05 \mathrm{~mm})$ and kept in a closed glass bottle until used.

Tartrazine (Figure 1), trisodium-5-hydroxy-1-(4-sulfonatophenyl)4-(4-sulfonatophenylazo)- $H$-pyrazole-3-carboxylate is an azo dye (CI Number=19140, EEC Number=E-102) with molecular formula

*Corresponding author: Mohammed A Kassem, Department of Chemistry, Faculty of Science, Benha University, Benha, Egypt, Tel:966532175442; Fax: 2133222578; E-mail: maa_kassem@hotmail.com

Received December 21, 2013; Accepted February 04, 2014; Published February 06, 2014

Citation: Kassem MA, El-Sayed GO (2014) Adsorption of Tartrazine on Medical Activated Charcoal Tablets under Controlled Conditions. J Environ Anal Chem 1: 102. doi: $10.4172 / 2380-2391.1000102$

Copyright: (c) 2014 Kassem MA, et al. This is an open-access article distributed under the terms of the Creative Commons Attribution License, which permits unrestricted use, distribution, and reproduction in any medium, provided the original author and source are credited. 


\begin{tabular}{|l|l|c|c|}
\hline Activated Carbon & Component & Amount/tablet $\mathbf{( m g )}$ & $\mathbf{\%} \mathbf{w} / \mathbf{w}$ \\
\hline \multirow{5}{*}{ AC1 } & Senna leaf & 105 & 29.09 \\
\cline { 2 - 4 } & Rhubarb extract & 25 & 6.92 \\
\cline { 2 - 4 } & Activated vegetable charcoal & 180 & 49.86 \\
\cline { 2 - 4 } & Sulphur (sublimated) & 50 & 13.85 \\
\cline { 2 - 4 } & Peppermint piperitae oil & 0.5 & 0.14 \\
\cline { 2 - 4 } & Fennel oil & 0.5 & 0.14 \\
\hline \multirow{4}{*}{ AC2 } & Belladonna & 10 & 2.77 \\
\cline { 2 - 4 } & Charcoal & 100 & 27.77 \\
\cline { 2 - 4 } & Di iodohydroxyquinoline & 125 & 34.72 \\
\cline { 2 - 4 } & Phthalyl Sulphathiazole & 125 & 34.72 \\
\hline
\end{tabular}

Table 1: Composition of commercial activated carbon tablets.<smiles>O=C(O[Na])c1nn(-c2ccc(S(=O)(=O)O[Na])cc2)c(O)c1/N=N/c1ccc(S(=O)(=O)O[Na])cc1</smiles>

Figure 1: Chemical structure of tartrazine.

$\mathrm{C}_{16} \mathrm{H}_{9} \mathrm{~N}_{4} \mathrm{Na}_{3} \mathrm{O}_{9} \mathrm{~S}_{2}$ and molecular weight 534.4 was obtained from Fluka. All other reagents were of A.R. grade.

\section{Apparatus}

Absorbance measurements were performed a double-beam JascoV-530 (UV-Vis) spectrophotometer (Japan). The solution $\mathrm{pH}$ has been measured with a pH-meter model HI 8014, HANNA Instruments (Italy).

\section{Adsorption studies}

A $500 \mathrm{mg} \mathrm{L}^{-1}$ stock solution was prepared by dissolving the required amount of dye in deionised water. Working solutions of the desired concentrations were obtained by successive dilution. Dye concentrations were analyzed before and after adsorption using a double-beam spectrophotometer at $428 \mathrm{~nm}$ versus deionized water as blank. After centrifugation at $5000 \mathrm{rpm}$, the concentrations of tartrazine in supernatant were measured and average values of two replicates were taken for each determination.

Batch adsorption experiments were carried out at temperature $\left(37^{\circ} \mathrm{C} \pm 1\right)$. A known weight of adsorbent material was added to $50 \mathrm{ml}$ of the dye solution with an initial concentration of 50 to $300 \mathrm{mg} \mathrm{L}^{-1}$. The contents were stirred thoroughly using a magnetic stirrer with a speed of $100 \mathrm{rpm}$ after adding the required dose of adsorbents (4-20 g $\left.\mathrm{L}^{-1}\right)$ for a specific period of contact time (5-120 min). The $\mathrm{pH}$ of the test solution was adjusted to the required value by adding either $1 \mathrm{M} \mathrm{HCl}$ or $1 \mathrm{M} \mathrm{NaOH}$ solution. After equilibrium, the final concentration $\left(C_{\mathrm{e}}\right)$ was determined and the percentage removal of dye was calculated using the following relationship:

$$
\% \text { Dye Removal }=\frac{C_{0}-C_{e}}{C_{0}} \times 100
$$

Where $C_{0}$ and $C_{\mathrm{e}}$ are the initial and final (at equilibrium) concentrations of dye $\left(\mathrm{mg} \mathrm{L}^{-1}\right)$, respectively

\section{Results and Discussion}

\section{Effect of initial $\mathrm{pH}$}

The effect of solution acidity on tartrazine sorption by medical activated carbon was studied in the initial $\mathrm{pH}$ range of 1.5-11.0 and is shown in Figure 2. The adsorption studies were carried out at $37^{\circ} \mathrm{C}$. A typical $\mathrm{pH}$ versus percentage removal of the dye showed a remarkable decrease in percentage removal of dye at higher $\mathrm{pH}$ values. The decrease in the uptake of dye above $\mathrm{pH} 6.0$ and thereafter no change in the adsorbed amount were observed. Maximum uptake of the dye (43.4 and 56.2\%) was achieved at $\mathrm{pH} 1.5$ for $\mathrm{AC} 1$ and $\mathrm{AC} 2$, respectively. Therefore, $\mathrm{pH} 1.5$ was selected as an optimum value for performing subsequent studies. This $\mathrm{pH}$ value is also the approximate $\mathrm{pH}$ of the human stomach. The result obtained clearly indicates increase of protonation due to neutralization of negative charge at the surface of the adsorbents, which facilitates diffusion and provides more active surface of the adsorbents, resulting thereby greater adsorption at their surfaces. The $\mathrm{pH}$ of solution controls the electrostatic interactions between the adsorbent and the adsorbate. A decrease in the percentage removal with increase in $\mathrm{pH}$ may be due to deprotonation, which retards the electrostatic forces between sorbent and sorbate that leads to reduced sorption capacity [18]. The effect of $\mathrm{pH}$ on the adsorption capacity of AC is in agreement with the previously reported results for adsorption of tartrazine from aqueous solutions by hen feathers [8] and some waste materials [9].

\section{Effect of contact time}

The effect of contact time between $\mathrm{AC}$ and tartrazine solution was studied for $\mathrm{AC} 1$ and $\mathrm{AC} 2$ using a constant concentration $(50 \mathrm{mg} /$ $\mathrm{ml}$ ) of dye solution at $37^{\circ} \mathrm{C}$. The adsorption of tartrazine dye onto $\mathrm{AC}$ has been investigated as a function of time in the range of 5-120 $\mathrm{min}$ at constant stirring rate of $100 \mathrm{rpm}$. Figure 3 shows percentage removal of the dye with contact time. As seen in Figure 3, a higher removal percentage of tartrazine dye is obtained at the beginning of the adsorption. Quantitative adsorption of dye from solution was determined within about $90 \mathrm{~min}$. Therefore, $90 \mathrm{~min}$ stirring time was found to be appropriate for maximum adsorption and was used in all subsequent measurements.

\section{Effect of initial dye concentration}

The effect of initial dye concentration in the range of 50 to 300 mg $\mathrm{L}^{-1}$ tartrazine on adsorption efficiency onto $\mathrm{AC} 1$ and $\mathrm{AC} 2$ was investigated and is shown in Figure 4. It is observed from the figure that the percentage tartrazine removal decreased with the increase in initial concentration of tartrazine. Though the percent adsorption

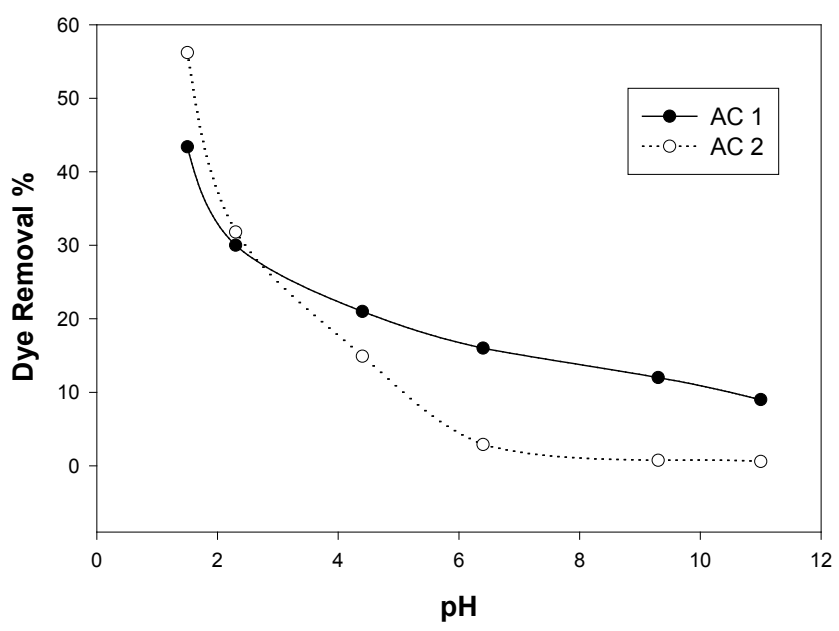

Figure 2: Effect of $\mathrm{pH}$ on the percent removal of tartrazine at equilibrium onto $\mathrm{AC} 1$ and $\mathrm{AC} 2$ at $37^{\circ} \mathrm{C}, \mathrm{C}_{0} 100 \mathrm{mg} \mathrm{L}^{-1}$ and $\mathrm{AC}$ dose $4 \mathrm{~g} \mathrm{~L}^{-1}$. 


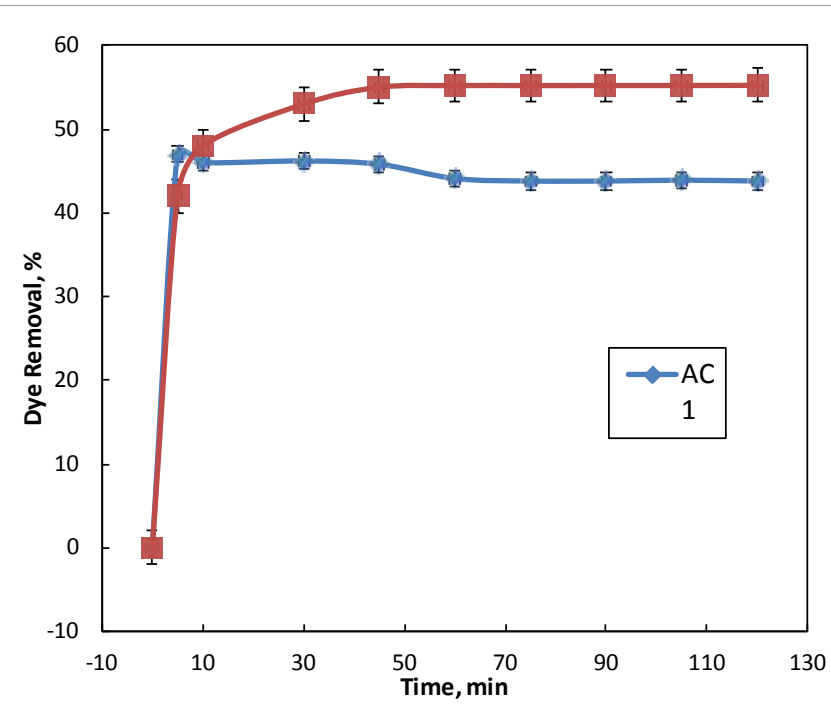

Figure 3: Effect of contact time on the percent removal of tartrazine onto $A C 1$ and $\mathrm{AC} 2$ at $\mathrm{pH} 1.5$, temperature $37^{\circ} \mathrm{C}, \mathrm{C}_{0} 100 \mathrm{mg} \mathrm{L}^{-1}$ and $\mathrm{AC}$ dose $4 \mathrm{~g} \mathrm{~L}^{-1}$.

decreased with increase in initial dye concentration, the actual amount of dye adsorbed per unit mass of adsorbent increased with increase in dye concentration in test solution. The unit adsorption for $\mathrm{AC} 1$ was increased from $10.85 \mathrm{mgg}^{-1}$ to $35.70 \mathrm{mgg}^{-1}$ as the tartrazine concentration in the test solution was increased from $50 \mathrm{mgL}^{-1}$ to 300 $\mathrm{mgL}^{-1}$. Similarly, unit adsorption for AC2 was increased from 14.05 $\mathrm{mgg}^{-1}$ to $50.1 \mathrm{mgg}^{-1}$ as the dye concentration was increased from 50 $\mathrm{mgL}^{-1}$ to $300 \mathrm{mgL}^{-1}$.

The initial dye concentration provides the necessary driving force to overcome the resistance to the mass transfer of tartrazine between aqueous phase and the solid phase. The increase in initial dye concentration results also an increase in the interaction between dye molecules and AC surface. Therefore, the increase of the initial concentration of tartrazine enhances the adsorption uptake of the dye [19].

\section{Effect of activated carbon dose}

The influence of adsorbent dosage on equilibrium uptake was shown in Table 2. The adsorbent dosages were taken between 2-10 $\mathrm{gL}^{-1}$ at initial dye concentration of $50 \mathrm{mgL}^{-1}$. With the increasing of the activated carbon dose, the adsorption capacity increased. Increasing adsorbent dosage can be attributed to increased adsorbent surface area and the availability of more adsorption sites. The values of equilibrium concentration of dye $q_{\mathrm{e}}$ decreased with increasing the adsorbent dosage. This factor explaining this result is that adsorption sites remain unsaturated during the adsorption reaction whereas the number of sites available for adsorption site increases by increasing the adsorbent dose [20].

\section{Effect of stirring rate}

The effect of stirring rate on the dye adsorption at the adsorbent dosage of $0.10 \mathrm{~g} / 25 \mathrm{ml}$, initial dye concentration of $50 \mathrm{mgL}^{-1}, \mathrm{pH} 1.5$ was examined at equilibrium $(60 \mathrm{~min})$. The data obtained indicate that the adsorption capacity $\left(q_{\mathrm{e}}\right)$ decreased as the agitation speed increased from 100-400 rpm (Figure 5a). For an rpm of the 100, the sorption of the dye on AC has its maximum value. It is due the attractive force between dye and adsorption site increased to $100 \mathrm{rpm}$, but in higher stirring rate, the dye molecules do not have enough time for contact with sorbent active sites [21].

\section{Effect of salinity}

The effect of salinity on the adsorption of tartrazine on AC was examined by adding different amounts $\left(2-10 \mathrm{~g} \mathrm{~L}^{-1}\right)$ of $\mathrm{NaCl}$ to a constant concentration of tartrazine $\left(100 \mathrm{mg} \mathrm{L}^{-1}\right)$. The experiments were performed at $37^{\circ} \mathrm{C}$ and $\mathrm{pH}$ 1.5. As shown in Figure 5b, the increase of salt concentration caused a remarkable decrease of adsorption efficiency for the two activated carbon sample used. Ionic strength is one of the key factors affecting the electrical double layer (EDL) structure of a hydrated particulate. The increase in ionic strength leads to a decrease in EDL thickness and an increase in the amount of indifferent ions approaching the AC surface. Thus, the results obtained can be attributed in part to increased competition between tartrazine and $\mathrm{Na}^{+}$ions for surface sites with increasing the ionic strength [22].

\section{Sorption modeling}

To describe the equilibrium distribution of tartrazine between the AC surface and the aqueous solution phase, two different sorption models, Langmuir and Freundlich have been used. These models were also used to calculate the loading capacity of the two forms of AC examined in this study.

\section{Langmuir isotherm}

The most widely used isotherm equation [23] for modeling of the sorption equilibrium data is the Langmuir isotherm. This model assumes the uniform energies of adsorption onto the surface without any transmigration of adsorbate in the plane of the surface. Langmuir

\begin{tabular}{|l|c|c|c|c|}
\hline \multirow{2}{*}{$\begin{array}{l}\text { Activated Charcoal } \\
\text { Dose (g L-1) }\end{array}$} & \multicolumn{2}{|c|}{ AC1 } & \multicolumn{2}{c|}{ AC2 } \\
\hline 4 & \% Removal & $\left.\mathbf{q}_{\mathbf{e}} \mathbf{~ ( m g ~ g ~}^{-1}\right)$ & \% Removal & $\left.\mathbf{q}_{\mathbf{e}} \mathbf{m g ~ g}^{-1}\right)$ \\
\hline 8 & 31.84 & 7.95 & 37.00 & 9.25 \\
\hline 12 & 52.20 & 6.53 & 56.70 & 7.09 \\
\hline 16 & 63.00 & 5.25 & 66.20 & 5.52 \\
\hline 20 & 67.00 & 4.19 & 70.40 & 4.40 \\
\hline
\end{tabular}

Table 2: Effect of activated carbon dose on percent removal at equilibrium.

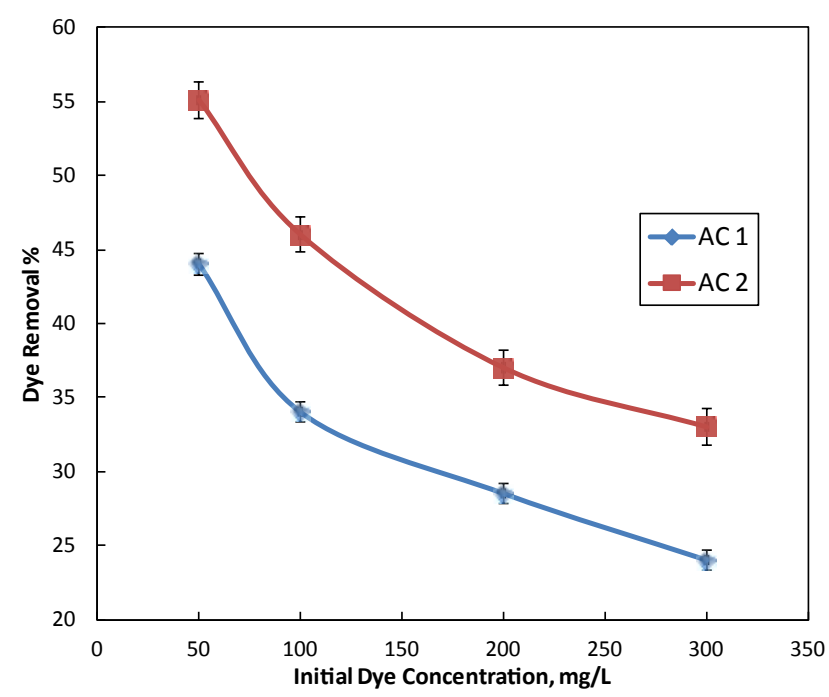

Figure 4: Effect of initial dye concentration on percent removal at equilibrium at temperature $37^{\circ} \mathrm{C}$ and $\mathrm{AC}$ dose $4 \mathrm{~g} \mathrm{~L}^{-1}$. 

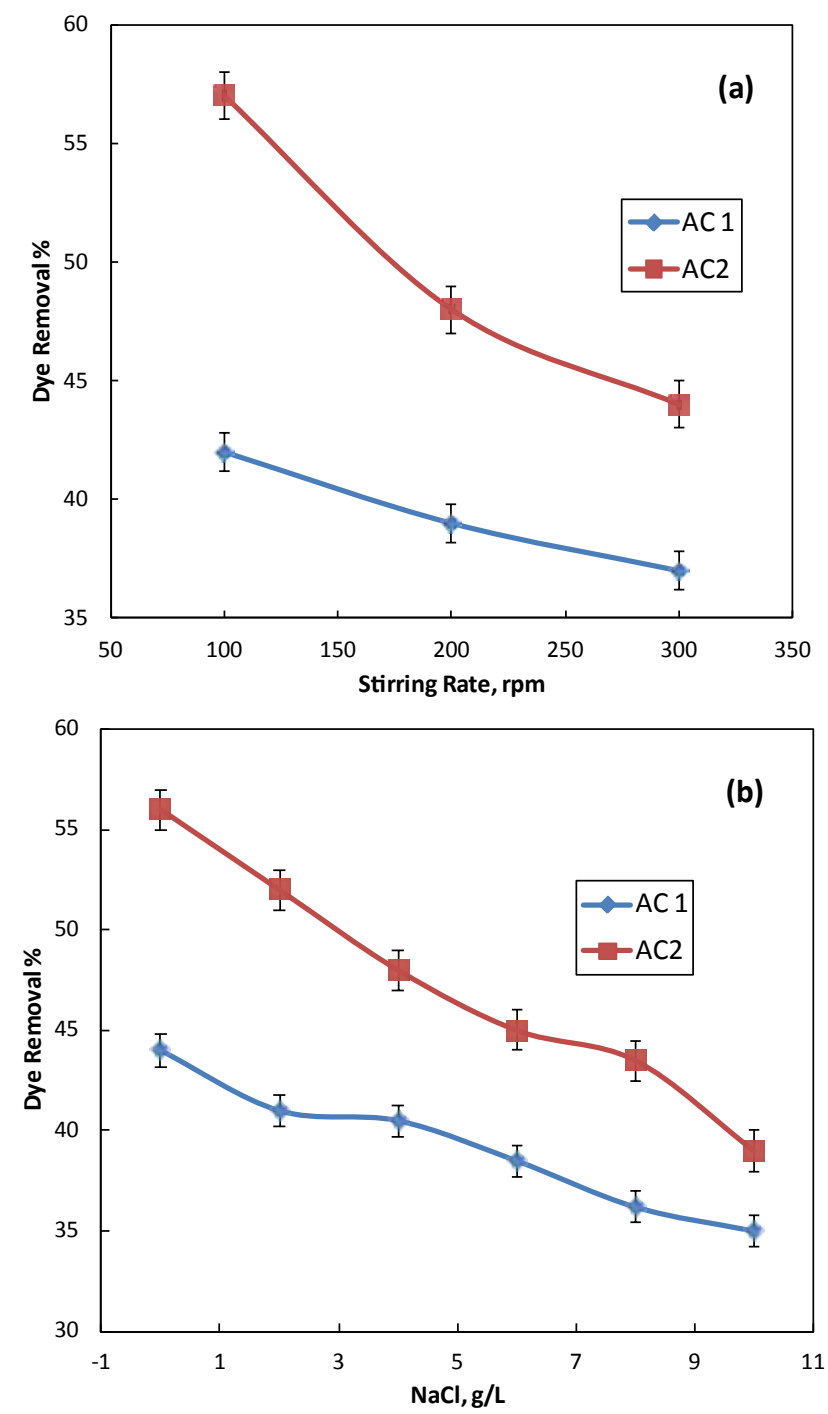

Figure 5: Effect of (a) stirring rate and (b) salinity on the percent removal of tartrazine onto $\mathrm{AC} 1$ and $\mathrm{AC} 2$ at equilibrium at temperature $37^{\circ} \mathrm{C}, \mathrm{C}_{0} 100 \mathrm{mg}$ $\mathrm{L}^{-1}$ and $\mathrm{AC}$ dose $4 \mathrm{~g} \mathrm{~L}^{-1}$.

sorption is a model based on the physical hypothesis that there are no interaction between adsorbed molecules and the adsorption energy over the entire coverage surface. This model imposes that a particular site of the adsorbent is occupied by an adsorbate molecule; no further adsorption takes place at that site, i.e. forming a monolayer of adsorbed species. The linear form of Langmuir isotherm equation is given by the equation [24]:

$$
\frac{C_{e}}{q_{e}}=\frac{1}{q_{m} K_{L}}+\frac{C_{e}}{q_{m}}
$$

where, $C_{e}$ is the equilibrium concentration of the dye $(\mathrm{mg} / \mathrm{L}), q_{e}$ is the amount of dye adsorbed per unit mass of $\mathrm{AC}\left(\mathrm{mg} \mathrm{g}^{-1}\right), q_{\mathrm{m}}$ and $K_{\mathrm{L}}$ are Langmuir constants related to adsorption capacity and rate of adsorption, respectively. The Langmuir constants can be evaluated from the slope and the intercept of linear equation (Table 3 ). The correlation coefficients of Langmuir isotherms, $R^{2}$ are 0.9501 and 0.9606 for $\mathrm{AC} 1$ and $\mathrm{AC} 2$, respectively. The essential characteristics of the Langmuir isotherm can be expressed in terms of a dimensionless constant separation factor $R_{\mathrm{L}}$ that is given in Equation. 3: The value of
$R_{\mathrm{L}}$ indicates the type of the isotherm to be either favorable $\left(0<R_{\mathrm{L}}<1\right)$, unfavorable $\left(R_{\mathrm{L}}>1\right)$, linear $\left(R_{\mathrm{L}}=1\right)$ or irreversible $\left(R_{\mathrm{L}}=0\right)$. The values of $R_{\mathrm{L}}$ were found to be $<1$ for the two adsorbents (Table 3 ) suggesting the isotherm to be favorable at the concentrations studied [25].

\section{Freundlich isotherm}

This model considers a heterogeneous adsorption surface that has unequalavailable sites with different energies of adsorption [26] and can be represented by:

$$
\ln q_{e}=\ln K_{f}+\frac{1}{n} \ln C_{e}
$$

where, $K_{\mathrm{f}}(\mathrm{mg} / \mathrm{g})$ and $n$ are Freundlich constants giving an indication of how favorable the adsorption process. $K_{\mathrm{f}}$ can be defined as the adsorption or distribution coefficient and represents the quantity of dye adsorbed onto the fibers for a unit equilibrium concentration. The slope of $1 / \mathrm{n}$ ranging between 0 and 1 is a measure of adsorption intensity or surface heterogeneity, becoming more heterogeneous as its value gets closer to zero [27].

To compare the Langmuir and Freundlich isotherm models, the experimental data have been statistically processed by linear regression. The regression equations of $y=a x+b$ type and the obtained values of the correlation coefficient, $R^{2}$, are given in Table 3 . It can be seen (Table 3) that the obtained data fit better to the Freundlich model than the Langmuir model (higher values for $R^{2}$ ), so the formation of more than one molecular layer of tartrazine on the surface of activated carbon appears to be achieved in the case of AC1 and AC2. The Langmuir and Freundlich isotherm plots are shown in Figures 6 a and b, respectively.

\section{Effect of temperature and thermodynamic studies}

The temperatures used in this study were 27,37 and $47^{\circ} \mathrm{C}$. As shown in Table 4, the adsorption capacity of the activated carbon decreased with increase in the temperature of the system. Activated carbon usually contains polar functional groups that can be involved in

\begin{tabular}{|l|c|c|c|c|c|c|c|}
\hline \multirow{2}{*}{ Adsorbent } & \multicolumn{4}{|c|}{ Langmuir Constants } & \multicolumn{3}{c|}{ Freundlich Constants } \\
\cline { 2 - 8 } & $\boldsymbol{q}_{\mathbf{m}}(\mathbf{m g} / \mathbf{g})$ & $\boldsymbol{K}_{\mathrm{L}}(\mathbf{L} / \mathbf{m g})$ & $\boldsymbol{R}^{2} \boldsymbol{R}_{\mathrm{L}}$ & \multicolumn{3}{c|}{$\boldsymbol{K}_{\mathrm{f}} \boldsymbol{n} \boldsymbol{R}^{\mathbf{2}}$} \\
\hline AC1 & 272.85 & 0.00071 & 0.9501 & $0.81-0.96$ & 0.97 & 1.583 & 0.9988 \\
\hline AC2 & 456.83 & 0.00079 & 0.9606 & $0.83-0.97$ & 0.83 & 1.768 & 0.9989 \\
\hline
\end{tabular}

Table 3: Langmuir and Freundlich adsorption constants for adsorption of tartrazine on $A C 1$ and $A C 2$.

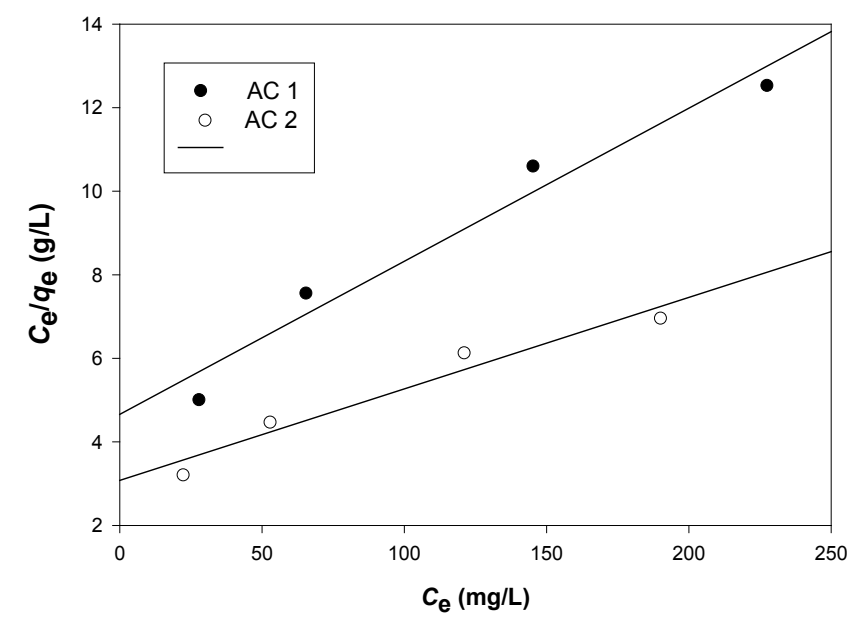

Figure 6a: Langmuir isotherms for adsorption of tartrazine onto AC1 and AC2 at $37^{\circ} \mathrm{C}$. 


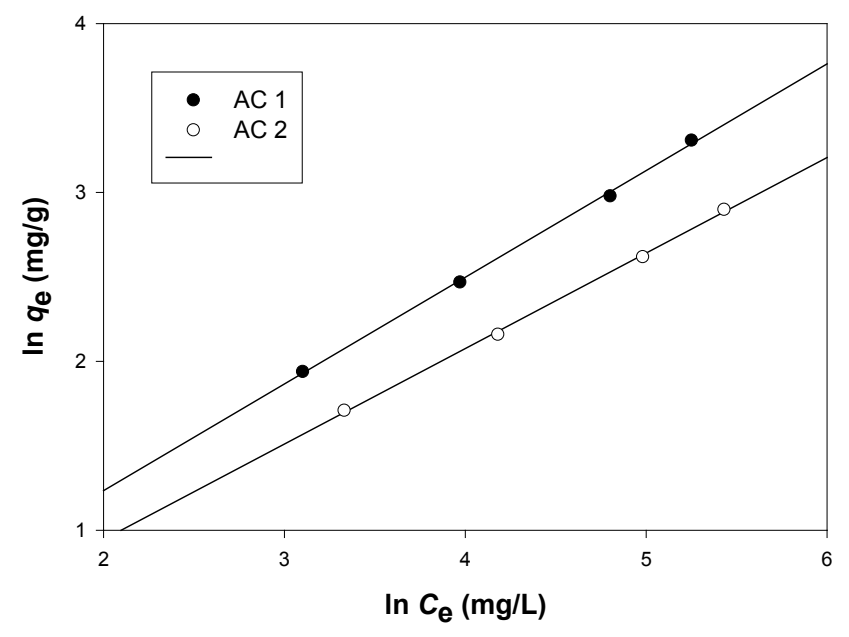

Figure 6b: Freundlich isotherms for adsorption of tartrazine onto AC1 and AC2 at $37^{\circ} \mathrm{C}$.

\begin{tabular}{|l|c|c|}
\hline \multirow{2}{*}{ Temperature $\left({ }^{\circ} \mathrm{C}\right)$} & \multicolumn{2}{|c|}{ Tartrazine Removal \% } \\
\cline { 2 - 3 } & AC1 & AC2 \\
\hline 37 & 47.40 & 60.0 \\
\hline 47 & 39.25 & 57.7 \\
\hline
\end{tabular}

Table 4: Effect of temperature on percent removal of tartrazine onto AC1 and AC2.

chemical bonding and are responsible for dye adsorption. The decrease in the extent of equilibrium adsorption of the dye with increasing the temperature indicated that a low temperature favored dye removal by adsorption and the adsorption of tartrazine onto AC was controlled by an exothermic process. The decrease of adsorption capacity with increasing temperature may be due to a decrease in the chemical potential of the adsorbate. It is known that decreasing sorption capacity with increasing temperature is mainly due to the weakening of sorptive forces between the active sites on the AC and anionic dye species, and also between adjacent dye molecules on the sorbed phase [28]. For a conventional mechanism of physisorption system, increase in temperature usually increases the rate of approach to equilibrium, but decreases the equilibrium capacity [29].

Thermodynamic parameters such as change in free energy $\Delta G^{\circ}(\mathrm{kJ} / \mathrm{mol})$, enthalpy $\Delta H^{\circ}(\mathrm{kJ} / \mathrm{mol})$ and entropy $\Delta S^{\circ}(\mathrm{J} / \mathrm{K} / \mathrm{mol})$ were determined. $\Delta G^{\circ}$ was calculated from the following equation [30]:

$$
\Delta G^{o}=-R T \ln K_{L}
$$

where: $K_{\mathrm{L}}$ is the Langmuir constant; $T$ is absolute temperature and $\mathrm{R}$ is the gas constant $(8.314 \mathrm{~J} / \mathrm{mol} \mathrm{K})$. The apparent $\Delta H^{\circ}$ and $\Delta S^{\circ}$ were calculated from adsorption data at different temperatures using the Van't Hoff equation [31]:

$$
\ln K_{L}=\frac{\Delta S}{R}-\frac{\Delta H}{R T}
$$

where: $K_{\mathrm{L}}$ is the Langmuir constant and T is the solution temperature(K). The magnitude of $\Delta H^{\circ}$ and $\Delta S^{\circ}$ was calculated from the slope and intercept from the plot of $\ln K_{\mathrm{L}} \mathrm{vs} 1 / T$ (Figure 7 ). The calculated thermodynamic parameters are given in Table 5 . The values of $\Delta H^{\circ}$ as calculated from Eq. (5) were-20.55 and $-6.97 \mathrm{~kJ} / \mathrm{mol}$ for AC1 and AC2, respectively. It is known that physical adsorption and chemisorptions can be classified, to a certain extent, by the magnitude of the enthalpy change. It is accepted that bonding strengths of $<84 \mathrm{~kJ} / \mathrm{mol}$ are typically those of physical adsorption type bonds. Chemisorption bond strengths can range from 40 to $120 \mathrm{~kJ} / \mathrm{mol}$ [32]. Based on this, the adsorption of tartrazine on activated carbon appears to be a physical adsorption process. Moreover it is expected that adsorption processes from liquid phase are exothermic due to the heat released after bond formation between solute and adsorbent [33]. The negative values of $\Delta S^{\circ}$ indicate the decrease of randomness at the solid/liquid interface during the adsorption process. The adsorption of tartrazine was nonspontaneous for $\mathrm{AC} 1$ and spontaneous for $\mathrm{AC} 2$ at the temperatures under investigation as indicated from the positive and negative values of free energy $\left(\Delta G^{o}\right)$ for the two adsorbents, respectively.

\section{Effect of nutrient additives}

It is likely that some effective nutrients may affect the adsorption efficiency of tartrazine on AC. Thus, the present part of this study was performed to develop the effect of some dietary components on the adsorption efficiency of tartrazine on AC. Different additives were added to the original dye solution in a fixed concentration of $2 \mathrm{gL}^{-1}$ and the results were compared to the tartrazine solution (Table 6). The data reveal the effect of the adsorption composition (Table 1). Table 7 shows the comparison of the proposed method to removal of tartrazine

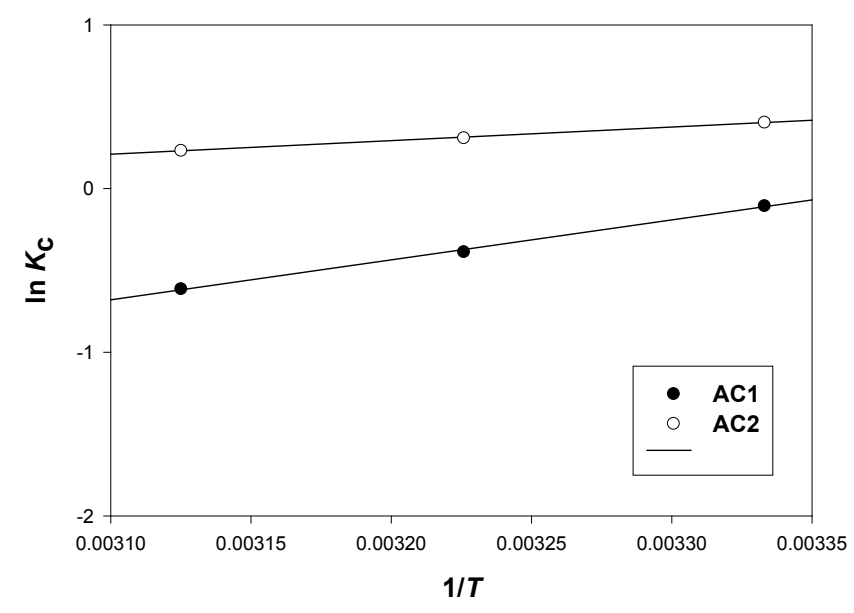

Figure 7: Plot of InK vs. 1/T for the estimation of thermodynamic parameters

\begin{tabular}{|c|c|c|c|c|}
\hline AC & Temperature $\left({ }^{\circ} \mathrm{C}\right)$ & $\Delta G^{\circ}$ & $\Delta H^{\circ}$ & $\Delta S^{\circ}$ \\
\hline \multirow[b]{3}{*}{ AC1 } & 27 & 262.48 & \multirow[b]{3}{*}{-20.55} & \multirow[b]{3}{*}{-69.44} \\
\hline & 37 & 1004.87 & & \\
\hline & 47 & 1647.33 & & \\
\hline \multirow[b]{3}{*}{ AC2 } & 27 & -1023.18 & \multirow[b]{3}{*}{-6.97} & \multirow[b]{3}{*}{-19.86} \\
\hline & 37 & -809.53 & & \\
\hline & 47 & -627.27 & & \\
\hline
\end{tabular}
for adsorption of tartrazine onto AC1 and AC2.

Table 5: Thermodynamic parameters of adsorption of tartrazine onto AC1 and AC2.

\begin{tabular}{|l|c|c|}
\hline \multirow{2}{*}{ Nutrient added* } & \multicolumn{2}{|c|}{ Effect on dye removal \% } \\
\cline { 2 - 3 } & AC1 & AC2 \\
\hline Glucose & 53.92 & 65.12 \\
\hline Succarose & 44.50 & 69.17 \\
\hline Glysine & 55.63 & 63.15 \\
\hline Lactose & 53.38 & 64.66 \\
\hline Saccharine & 43.60 & 66.90 \\
\hline Aspartame & 50.30 & 72.20 \\
\hline
\end{tabular}

Table 6: Effect of nutrients added on the percent removal of tartrazine onto AC1 and AC2. 


\begin{tabular}{|c|c|c|c|}
\hline Determination technique & Adsorbent & Optimum conditions & Ref. \\
\hline FT-IR, SEM & Saw dust & $70 \mathrm{~min}, \mathrm{pH} 3$ & [35] \\
\hline X-ray diffraction & Bottom Ash and De-Oiled Soya & $3-4 \mathrm{~h}, \mathrm{pH} 2$ & [9] \\
\hline Spectrophotometry & Hen feathers & $\mathrm{pH} 2$ & [8] \\
\hline Spectrophotometry FT-IR analysis & Polystyrene anion exchangers & $20 \mathrm{~min}, 50^{\circ} \mathrm{C}$ & [10] \\
\hline IR, BET, SEM, TGA & Melamine-formaldehyde-Tartaric acid resin & $15-30^{\circ} \mathrm{C}$ & {$[36]$} \\
\hline Spectrophotometry & Polyaniline & $\mathrm{pH}$ range of $2-5$ & [37] \\
\hline Spectrophotometry & Electrocoagulation & ------ & [38] \\
\hline Spectrophotometry & Titanium dioxide & $\mathrm{pH} 11$ & [39] \\
\hline Spectrophotometry & Medical tablets of activated charcoal & $\mathrm{pH} 1.5$ and $37^{\circ} \mathrm{C}$ & This work \\
\hline
\end{tabular}

Table 7: Comparison of the proposed method to removal of Tartrazine with those reported previously.

with those reported previously. It shows that the proposed method is the first one in terms of the use of medical products and are commonly used to removal of tartrazine by high rate and efficiency.

\section{Conclusion}

The present study was carried out to examine the ability of commercial activated carbon tablets to adsorb artificial coloring agent tartrazine from aqueous solutions. Activated carbon tablets appeared to be a promising adsorbent for the removal of tartrazine from aqueous solutions under gastrointestinal-like conditions. The optimum $\mathrm{pH}$ for removal process was around 1.5. The extent of dye removal increased with decreased initial concentration of the dye and also increased with increased contact time and AC dose. Adsorption of tartrazine onto the two types of AC occurred in a short time and reached equilibrium in about $90 \mathrm{~min}$ for the two types of tablets. AC2 had a higher adsorption capacity than AC1 under the same conditions. The results obtained are well fitted in the linear forms of Freundlich more than Langmuir adsorption isotherms for either $\mathrm{AC} 1$ or AC2. The adsorption process was found to be exothermic. The adsorption process is exothermic and non-spontaneous for AC1 and spontaneous for AC2. The values of entropy change suggested the probability of favorable adsorption. Medical activated charcoal tablets appear as a very prospective adsorbent for the removal of tartrazine from aqueous solution.

\section{References}

1. Bhatia MS (2000) Allergy to tartrazine in psychotropic drugs. J Clin Psychiatry 61: 473-476.

2. Mac Cara ME (1982) Tartrazine: a potentially hazardous dye in Canadian drugs. Can Med Assoc J 126: 910-914.

3. Rosenhall $L$ (1982) Evaluation of intolerance to analgesics, preservatives and food colorants with challenge tests. Eur J Respir Dis 63: 410-419.

4. Pohl R, Balon R, Berchou R, Yeragani VK (1987) Allergy to tartrazine in antidepressants. Am J Psychiatry 144: 237-238.

5. Collins-Williams C (1985) Clinical spectrum of adverse reactions to tartrazine. J Asthma 22: 139-143.

6. Dipalma JR (1990) Tartrazine sensitivity. Am Fam Physician 42: 1347-1350.

7. Baumgardner DJ (1989) Persistent urticaria caused by a common coloring agent. Postgrad Med 85: 265-266.

8. Mittal A, Kurup L, Mittal J (2007) Freundlich and Langmuir adsorption isotherms and kinetics for the removal of Tartrazine from aqueous solutions using hen feathers. J Hazard Mater 146: 243-248.

9. Mittal A, Mittal J, Kurup L (2006) Adsorption isotherms, kinetics and column operations for the removal of hazardous dye, Tartrazine from aqueous solutions using waste materials--Bottom Ash and De-Oiled Soya, as adsorbents. J Hazard Mater 136: 567-578.

10. Wawrzkiewicz M, Hubicki Z (2009) Removal of tartrazine from aqueous solutions by strongly basic polystyrene anion exchange resins. J Hazard Mater 164: 502-509.

11. Mishra AK, Arockiadoss T, Ramaprabhu S (2010) Study of removal of azo dye by functionalized multi walled carbon nanotubes. Chem Engin J 162: 10261034

12. Ozsoy HD, Van Leeuwen JH (2010) Removal of color from fruit candy waste by activated carbon adsorption. J Food Eng 101: 106-112.

13. Phan NH, Rio S, Faur C, Le Coq L, Le Cloirec $P$, et al. (2006) Production of fibrous activated carbons from natural cellulose (jute, coconut) fibers for water treatment applications. Carbon 44:2569-2577.

14. Shi Q, Zhang J, Zhang C, Li C, Zhang B, et al. (2010) Preparation of activated carbon from cattail and its application for dyes removal. J Environ Sci (China) 22: 91-97.

15. Fierro V, Muñiz G, Basta AH, El-Saied H, Celzard A (2010) Rice straw as precursor of activated carbons: activation with ortho-phosphoric acid. J Hazard Mater 181: 27-34.

16. Erdinç N, Göktürk S, Tunçay M (2010) A study on the adsorption characteristics of an amphiphilic phenothiazine drug on activated charcoal in the presence of surfactants. Colloids Surf B Biointerfaces 75: 194-203.

17. Dasgupta A, Wahed A, Culton L, Olsen M, Wells A, et al. (2002) Actor Activated charcoal is more effective than equilibrium dialysis in removing Chinese medicines Chan Su and Dan Shen from serum and activated charcoal also prevents further absorption of these agents from G.I. tract in mice: monitoring the effect in clinical laboratory by measuring digoxin activity in serum. Clic Chim Acta 324: 51-59.

18. El Nemr A, Khaled A, Abdelwahab O, El-Sikaily A (2008) Treatment of wastewater containing toxic chromium using new activated carbon developed from date palm seed. J Hazard Mater 152: 263-275.

19. Kumar PS, Ramalingam S, Senthamarai C, Niranjanaa M, Vijayalakshmi $P$, et al. (2010) Adsorption of dye from aqueous solution by cashew nut shell: Studies on equilibrium isotherm, kinetics and thermodynamics of interactions. Desalination 261: 52-60.

20. Han R, Li H, Li Y, Zhang J, Xiao H, et al. (2006) Biosorption of copper and lead ions by waste beer yeast. J Hazard Mater 137: 1569-1576.

21. Hashemian S, Dadfarnia S, Nateghi MR, Gafoori F (2008) Sorption of acid red 138 from aqueous solutions onto rice bran. Afric J Biotechno 17: 600-605.

22. Weng CH, Lin YT, Tzeng TW (2009) Removal of methylene blue from aqueous solution by adsorption onto pineapple leaf powder. J Hazard Mater 170: 417424.

23. Amin NK (2009) Removal of direct blue-106 dye from aqueous solution using new activated carbons developed from pomegranate peel: adsorption equilibrium and kinetics. J Hazard Mater 165: 52-62.

24. Langmuir I (1918) The adsorption of gases on plane surfaces of glass, mica and platinum. J Am Chem Soc 40: 1361-1403.

25. El-Sayed GO (2010) Removal of water hardness by adsorption on peanut hull. $\mathrm{J}$ Int Environ Sci 5: 47-55.

26. Freundlich $\mathrm{H}$ (1906) Over the adsorption in solution. Z Phys Chem A 57: 385 470.

27. Amin NK (2008) Removal of reactive dye from aqueous solutions by adsorptiononto activated carbons prepared from sugarcane bagasse pith Desalin 223: 152-161.

28. Ho YS, Chiang TH, Hsueh YM (2005) Removal of basic dye from aqueous solution using tree fern as a biosorbent. Process Biochem 40: 119-124.

29. Ofomaja AE, Ho YS (2007) Equilibrium sorption of anionic dye from aqueous solution by palm kernel fibre as sorbent. Dyes Pigm 74: 60-66. 
Citation: Kassem MA, El-Sayed GO (2014) Adsorption of Tartrazine on Medical Activated Charcoal Tablets under Controlled Conditions. J Environ Anal Chem 1: 102. doi:10.4172/2380-2391.1000102

30. Gupta VK, Ali I, Suhas, Mohan D (2003) Equilibrium uptake and sorption dynamics for the removal of a basic dye (basic red) using low-cost adsorbents. J Colloid Interface Sci 265: 257-264.

31. Namasivayam C, Kavitha D (2002) Removal of Congo Red from water by adsorption onto activated carbon prepared from coir pith, an agricultural solid waste. Dyes Pigm 54: 47-58.
32. Alkan M, Demirbaş O, Celikçapa S, Doğan M (2004) Sorption of acid red 57 from aqueous solution onto sepiolite. J Hazard Mater 116: 135-145.

33. Mattson J, Mark HL (1971) Activated carbon: surface chemistry and adsorption from solution. New York: Marcel Dekker, Inc. 